Йзв. АН Эстонии. Х̆нм., 1989, 38, № 4, 242-247

удК 669.822

Г. РАЯЛО, О. КИРРЕТ,

\title{
СУЛЬФИТНЫЙ МЕТОД ГИДРОМЕТАЛЛУРГИЧЕСКОЙ ПЕРЕРАБОТКИ ЗОЛЫ ДИКТИОНЕМОВОГО АРГИЛЛИТА ЭСТОНии
}

\author{
(Представил Ю. Канн)
}

В северной части Эстонии находятся большие запасы диктионемового аргиллита, содержащего, кроме органического вещества, сернистых соединений и других макрокомпонентов, еще ряд рассеянных элементов, в том числе уран, ванадий, титан, молибден и т.д. В настоящее время аргиллитовая руда не находит энергетического и металлургического применения ввиду низких концентраций перечисленных сопутствующих металлов. Экономически это невыгодно. Однако ситуация может измениться, когда будет разработан экологически приемлемый и экономически обоснованный способ добычи фосфорита, выше слоев которого и залегает аргиллит.

Исследование процесса выщелачивания урана, ванадия и других металлов из аргиллита или из его золы водным раствором сернистого ангидрида представляет двоякий интерес. Во-первых, экологический. Выщелачивание как вредный для природы процесс может иметь место при сбрасывании аргиллита вместе с пиритом в отвал и последующем его самовозгорании, как это сейчас и происходит при карьерной добыче фосфорита. Во-вторых, выщелачивание сульфитным раствором может рассматриваться как одна из возможностей химического обогащения бедной полиметаллической руды. Ведь достоинство сульфитного метода состоит не только в растворении таких ценных компонентов, как уран, ванадий, молибден и т. д., но и в последующей десорбции растворенного сернистого ангидрида из раствора с одновременным осаждением концентрата, во много раз более богатого этими компонентами. На возможность сульфитного выщелачивания урана из руд указано уже давно [']. Метод сернистокислотного выщелачивания с последующим осаждением при кипячении раствора применяется и в производстве чистого глинозема из алюминиевых руд $\left[^{2}\right]$.

Извлечение металлических компонентов из аргиллита раствором сернистого ангидрида в значительной мере зависит от условий его терА мической переработки или сжигания. В качестве примера рассмотрим выщелачивание урана и других элементов из зол бедного аргиллита Маардуского месторождения и концентрата его органического вещества. Последний получали флотационным обогащением тонкоизмельченного аргиллита (93\% материала - 0,1 мм). Содержания основных компонентов в аргиллите и продукте его обогащения приведены в таблице. Озоление обоих продуктов проводили в лабораторной печи, снабженной термопарой для измерения и регулирования температуры. Температуру печи поддерживали постоянной в течение 2 ч. Полученные при разных температурах золы смешивали с водой в соотношении $1: 20$, и суспензии насыщали при $20^{\circ} \mathrm{C}$ и атмосферном давлении сернистым ангидридом. После выщелачивания суспензию разделяли фильтрацией, полученный кек промывали водой. Водные фазы объединяли, полученный раствор подвергали анализу. 


\begin{tabular}{|c|c|c|c|c|}
\hline Компонент & $\begin{array}{l}\text { Исходный } \\
\text { аргиллит, } \\
\% \text { от с. в. }\end{array}$ & $\begin{array}{c}\text { Концентрат } \\
\text { органического } \\
\text { вещества, } \\
\% \text { от с. в. }\end{array}$ & $\begin{array}{c}\text { Сульфитный } \\
\text { раствор, } \\
\text { г/л }\end{array}$ & $\begin{array}{c}\text { Сульфитный } \\
\text { концентрат, } \\
\% \text { от с. в. }\end{array}$ \\
\hline
\end{tabular}

\section{Органическое}

вещество

$\mathrm{S}$ (общ.)

$\mathrm{SO}_{2}$

$\mathrm{SO}_{3}$

$\mathrm{Al}_{2} \mathrm{O}_{3}$

$\mathrm{Fe}_{2} \mathrm{O}_{3}$

$\mathrm{U}$

V

Mo

\section{4,3}

2,07

11,0

4,30

0,0035

0,058

0,011

\section{4,1}

3,66

105,7

11,1

29,3

32,0

16,7

6,14

0,10

0,68

0,12

Результаты опытов показали, что практически полное равновесие по растворимости урана, ванадия и других компонентов достигается уже в первые 3 мин, продолжение выщелачивания не оказывает заметного влияния на извлечение этих элементов. Обнаруживается также влияние температуры озоления на последующее выщелачивание металлических компонентов. Температуры озоления, при которых достигается их максимальное извлечение, для каждого элемента различны: для урана 400$450{ }^{\circ} \mathrm{C}$ (рис. 1), молибдена $700^{\circ} \mathrm{C}$, ванадия $850-900^{\circ} \mathrm{C}$. По степени извлечения последние два элемента уступают урану. Что касается макрокомпонентов, то максимальная растворимость $\mathrm{K}_{2} \mathrm{O}$ приходится на $500^{\circ} \mathrm{C}, \mathrm{Al}_{2} \mathrm{O}_{3}$ — на $700-800^{\circ} \mathrm{C}$. При этом извлечение этих макрокомпонентов остается ниже $4 \%$. При $400-500^{\circ} \mathrm{C}$ растворимость $\mathrm{Fe}_{2} \mathrm{O}_{3}$ резко падает и при дальнейшем повышении температуры озоления практически не меняется (рис. 2). Следовательно, имеет место селективность сульфитного выщелачивания, что позволяет при оптимальном выборе температуры сжигания отделить уран и другие рассеянные элементы от макрокомпонентов, в частности от железа.

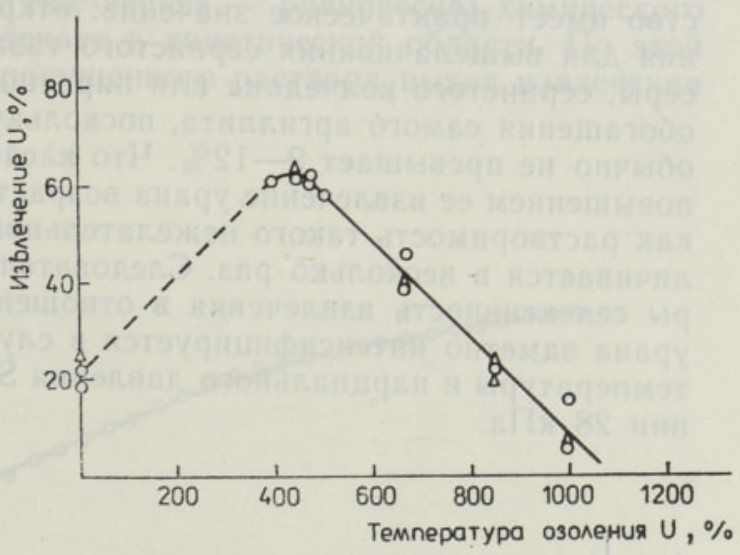

Рис. 1. Извлечение урана в зависимости от температуры озоленения: $\bigcirc-$ аргиллит, $\triangle$ - концентрат органического вещества.

Были изучены также возможности сульфитного выщелачивания рассеянных элементов из зол, полученных разными методами: медленным низкотемпературным сжиганием кускового аргиллита в шахте, сжиганием в псевдоожиженном слое более тонкодисперсного материала и низкотемпературной термической переработкой кускового аргиллита в шахтном генераторе. В последнем случае, при выборе оптимальных условий сжигания, удалось довести извлечение урана из золы до 76\%. Из остатка же коксования аргиллита, наоборот, его выход незначителен. При достаточном времени контакта растворимость урана и других металлических компонентов практически не зависит от дисперсности материала (в пределах 0,1-5 мм) (рис. 3). 


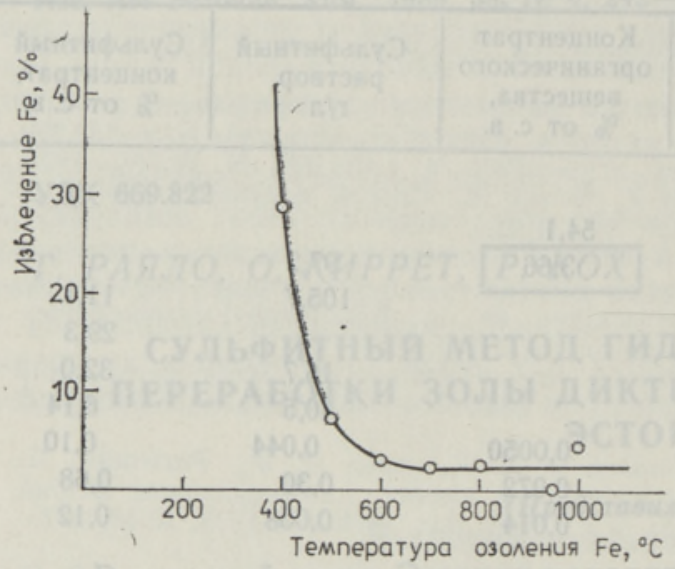

Рис. 2. Извлечение железа в зависимости от температуры озоления.

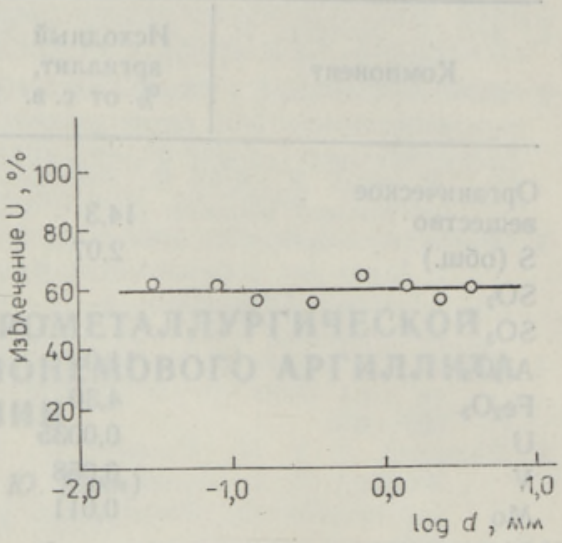

Рис. 3. Извлечение урана в зависимости от размера частиц золы $(d)$.

Извлечение урана из золы возрастает с повышением парциального давления сернистого ангидрида в газе, находящегося в равновесии с жидкой фазой, но резкий рост извлечения наблюдается лишь при парциальном давлении ниже 1 кПа. Дальнейшее его увеличение относительно мало влияет на растворимость урана (рис. 4). Это обстоятельство имеет практическое значение: открывается возможность применения для выщелачивания сернистого газа, выделяющегося при обжиге серы, сернистого колчедана или пиритного концентрата, полученного от обогащения самого аргиллита, поскольку содержание $\mathrm{SO}_{2}$ в таком газе обычно не превышает 9-12\%. Что касается влияния температуры, то с повышением ее извлечение урана возрастает лишь ненамного, в то время как растворимость такого нежелательного компонента, как железо, увеличивается в несколько раз. Следовательно, при повышении температуры селективность извлечения в отношении урана падает. Извлечение урана заметно интенсифицируется в случае одновременного увеличения температуры и парциального давления $\mathrm{SO}_{2}$ - до $75 \%$ при $75^{\circ} \mathrm{C}$ и давлении 28 кПа.

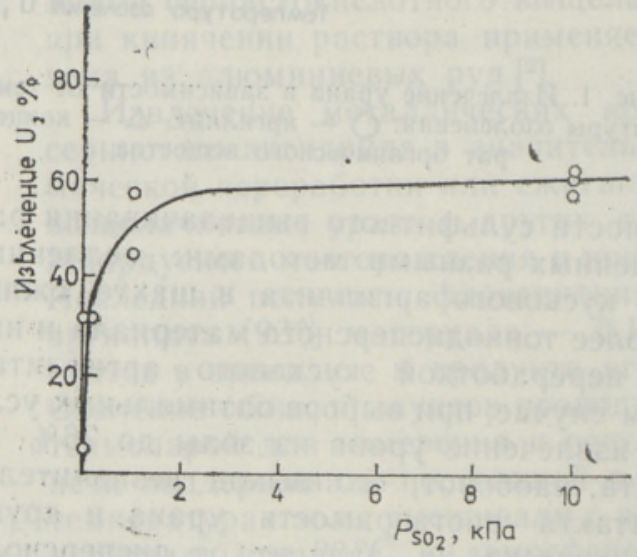

Рис. 4. Извлечение урана в зависимости от парциального давления $\mathrm{SO}_{2}$. . .

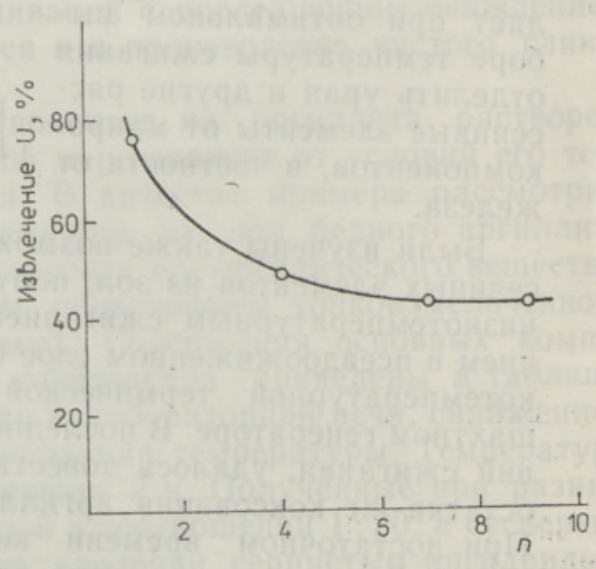

Рие. 5. Извлеченне урана в зависи. мости от количества рабочих циклов раствора $(n)$. 
Нами изучена возможность повторного использования отработанного раствора при растворении. Извлечение урана из генераторной золы аргиллита убывает с увеличением рабочих циклов раствора (рис. 5). Это объясняется главным образом недостаточной промывкой осадка в связи с желанием сохранить постоянным количество раствора. Укрупненными лабораторными опытами получен высокий выход урана при проведении процесса выщелачивания методом многоступенчатой противоточной репульпации.

Малая зависимость извлечения металлических компонентов от размера частиц, а также практически полное отсутствие в золах тонких глинистых фракций открывают возможности осуществления процееса выщелачивания перколяционным методом или же пропусканием раствора через колонны, заполненные зернистым материалом. В качестве примера рассмотрим результаты колонного выщелачивания урана и железа из золы сжигания маардуского аргиллита в псевдоожиженном слое. Опыт проводили в колонне из нержавеющей стали внутренним диаметром 46 мм и высотой слоя твердого материала 1,85 м. Направление движения раствора - снизу вверх. В ходе выщелачивания выявилось явное уменьшение скорости извлечения урана, в то время как скорость растворения железа оставалась практически постоянной (рис. 6). Әто обстоятельство, а также отмеченная выше большая зависимость извлечения железа от температуры объясняются разным кинетическим характером выщелачивания этих компонентов. Процесс выщелачивания урана протекает в области внутренней диффузии, где лимитирующим общую скорость процесса фактором является скорость диффузии в порах твердого материала. В то же время при растворении железа лимитирующим фактором является скорость (а еще вернее - равновесие) химического превращения, т.е. процесс протекает в кинетической области. По этой причине с ростом количества пропущенного раствора выход извлечения

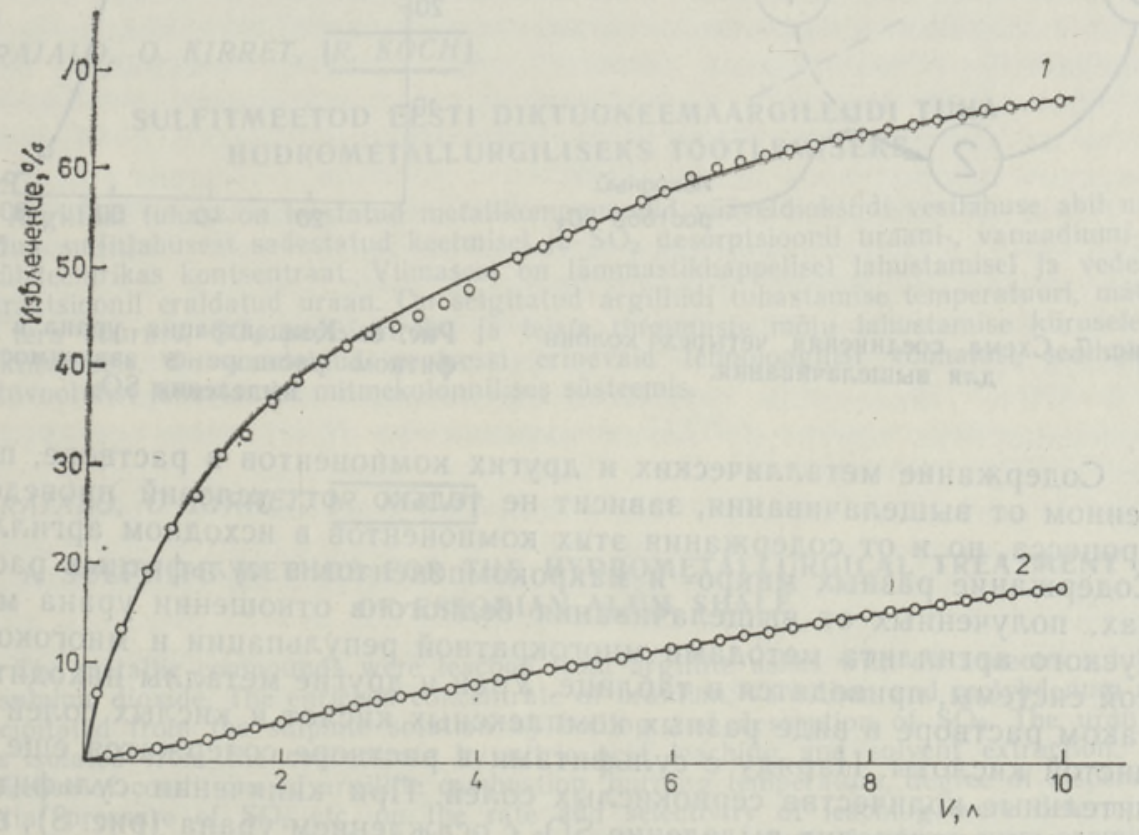

Рис. 6. Извлечение урана (1) и железа (2) в зависимости от количества пропущенного раствора. 
урана увеличивается (до $75 \%$ ), но это сопровождается падением селективности процесса, т. е. уменьшением степени отделения урана от нежелательных компонентов.

Изучена возможность проведения процесса выщелачивания на многоколонной установке, работающей по принципу противоточного двнжения раствора и твердого материала. Установка состояла из четырех колонн вышеприведенных размеров, соединенных в систему (рис. 7). Колонна 1 выключается из системы для промывки, выгрузки остатка и загрузки новой порции исходной золы. Через определенное время выключается из системы колонна 2, исходный раствор сернистого ангидрида направляется в нижнюю часть колонны 3, а отработанный раствор выводится из верхней части колонны 1. Таким образом, все колонны поочередно отключаются на выгрузку-загрузку и создается противоточное движение фаз, когда свежий раствор находится в контакте с наиболее отработанной золой, а отработанный, наоборот, с исходной золой. По результатам наших опытов, применение такой схемы позволяет, при сохранении примерно такого же выхода извлечения урана, как в случае одноколонного выщелачивания, сократить удельный расход сульфитного раствора примерно втрое и в значительной мере уменьшить выход железа в раствор.

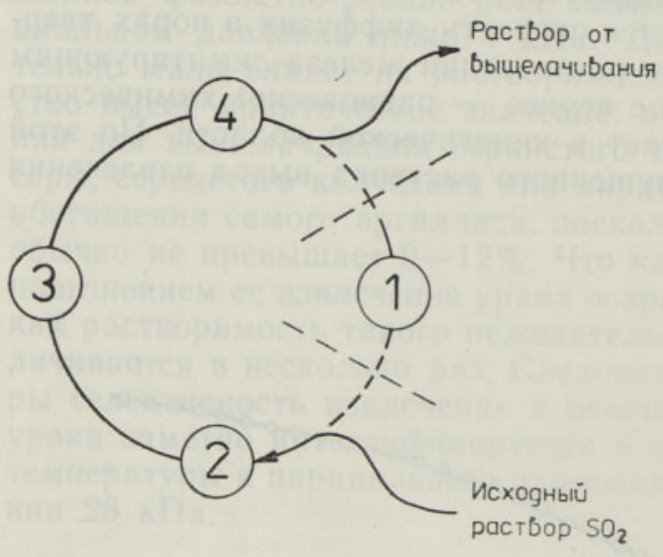

Рис. 7. Схема соединения четырех колонн для выщелачивання.

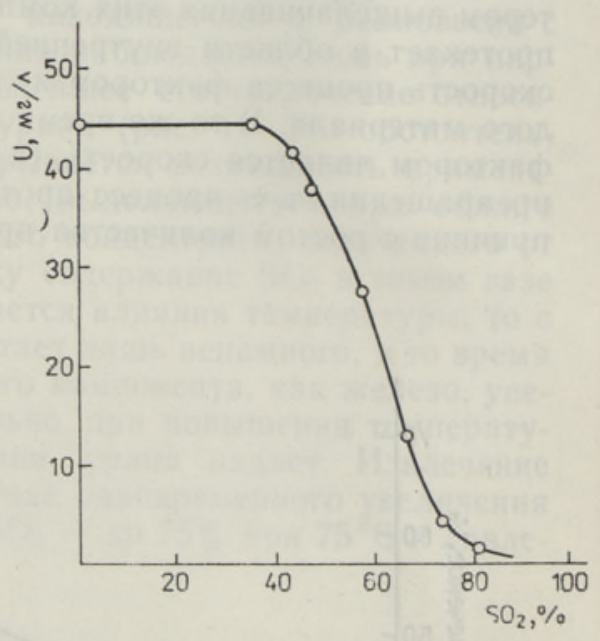

Рис. 8. Концентрация урана в сульфитном растворе в зависимости от выделения $\mathrm{SO}_{2}$.

Содержание металлических и других компонентов в растворе, полученном от выщелачивания, зависит не только от условий проведения процесса, но и от содержания этих компонентов в исходном аргиллите. Содержание разных микро- и макрокомпонентов в сульфитных растворах, полученных от выщелачивания бедного в отношении урана маардуского аргиллита методами многократной репульпации и многоколонной системы, приводятся в таблице. Уран и другие металлы находятся в таком растворе в виде разных комплексных кислот и кислых солей сернистой кислоты. Наряду с сульфитами в растворе содержатся еще значительные количества сернокислых солей. При кипячении сульфитного раствора происходит выделение $\mathrm{SO}_{2}$ с осаждением урана (рис. 8), ванадия, молибдена, алюминия и других металлических компонентов в виде нейтральных или основных сернистокислых, а частично и фосфорнокислых солей. Соединения железа в этих условиях осаждаются лишь в незначительном количестве. Одновременно с десорбцией $\mathrm{SO}_{2} \mathrm{pH}$ раствора повышается от 2 до 4,5 , 
Содержание урана в концентратах, осажденных из сульфитного раствора, колеблется в пределах $0,1-0,2 \%$, ванадия $0,4-0,7 \%$ и молибдена $0,1-0,3 \%$. Содержания этих элементов удваиваются при прокаливании концентрата до $600{ }^{\circ} \mathrm{C}$. В качестве примера в таблице приводится состав сұльфитного концентрата, полученного из золы маардуского аргиллита. Сравнивая концентрации расселнных элементов в концентрате и исход1:ой золе, можно видеть примерно 30-кратное обогащение по урану и более чем 10-кратное - по ванадию и молибдену.

Из сульфитного концентрата можно полностью выщелачивать уран If другие компоненты растворами минеральных кислот $\left(\mathrm{H}_{2} \mathrm{SO}_{4}, \mathrm{HNO}_{3}\right.$, $\mathrm{HCl})$, а из полученных растворов выделять эти компоненты известными мстодами [3]. Нами был использован азотнокислотный метод. Из получснного азотнокислого раствора выделяли уран путем двуступенчатой экстракции $30 \%$-ным раствором трибутилфосфата в керосине и трехступенчатой реэкстракцией водой. Процесс экстракции-реэкстракции проводили дважды. Суммарное извлечение урана из азотнокислого раствора составило $77 \%$. Из полученного раствора добавлением аммиакд осаждали диуранат аммония. Осадок отфильтровывали и прокаливали. Содержание $\mathrm{U}_{3} \mathrm{O}_{8}$ в готовом продукте было $97,2 \%$.

\section{ЛИ Т Е Р А Т У Р А}

1. Fester, G. A. Hydrometallurgie des Urans. Stuttgart, 1956.

2. Розенкноп 3. П., Василенко Н. А., Чернобаева М. М. и др. Комплексная переработка нефелина сернистым газом на глинозем, соли и концентрированный сернистый ангидрид // Тр. НИУИФ, 1960, вып. 169.

3. Громов Б. В. Введение в химическую технологию урана. М., 1978.

Ннститут химии

Академии наук Әстонской ССР
Поступила в редакщию $9 /$ III 1989

G. RAJALO, O. KIRRET, $\overline{\text { R. KOCH }}$

\section{SULFITMEETOD EESTI DIKTUONEEMAARGILLIIDI TUHA HODROMETALLURGILISEKS TOOOTLEMISEKS}

Argilliidi tuhast on leostatud metallkomponendid vääveldioksiidi vesilahuse abil ning saadud sulfitlahusest sadestatud keetmisel ja $\mathrm{SO}_{2}$ desorptsioonil uraani-, vanaadiumi- ja molübdeenirikas kontsentraat. Viimasest on lämmastikhappelisel lahustamisel ja vedelikekstraktsioonil eraldatud uraan. On selgitatud argilliidi tuhastamise temperatuuri, materjali tera suuruse, $\mathrm{SO}_{2}$ partsiaalrōhu ja teiste tingimuste mōju lahustamise kiirusele ja selektiivsusele. On vaadeldud protsessi erinevaid tehnoloogilisi võimalusi, sealhulgas vastuvoolulist lahustamist mitmekolonnilises süsteemis.

\section{G. RAJALO, O KIRRET, $\overline{\mid R . \mathrm{KOCH}}$}

\section{A SULPHITE METHOD FOR THE HYDROMETALLURGICAL TREATMENT OF ESTONIAN ALUM SHALE}

The metallic compounds were leached from argillite ashes with an aqueous solution of sulphur dioxide. The enriched concentrate of uranium, vanadium and molybdenum was precipitated from the sulphite solution by boiling and desorption of $\mathrm{SO}_{2}$. The uranium was isolated from the concentrate by nitric acid leaching and solvent extraction. The influence of conditions of argillite combustion, burning temperature, degree of dispersion, partial pressure of $\mathrm{SO}_{2}$ etc. on the rate and selectivity of leaching were determined. Several technological methods, including countercurrent column leaching, were examined. 